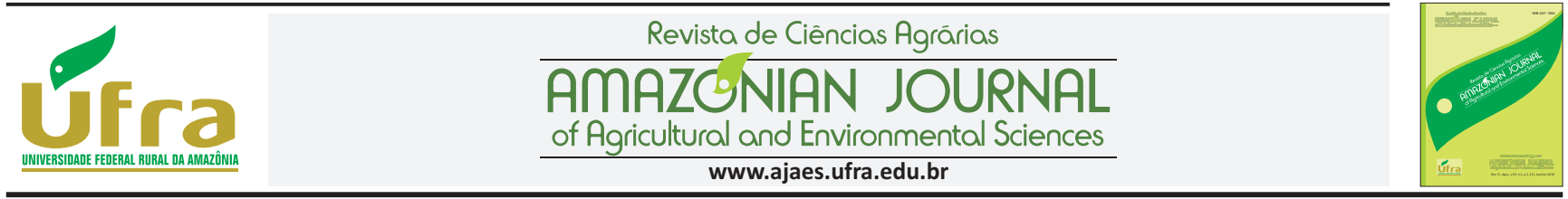

AUTORES:
Carla Cristina
Guimarães de Moraes ${ }^{1}$
Rosely Bianca dos
Santos Kuroda ${ }^{2}$
Ana Paula Vilhena
Beckman Pinho $^{3}$
Fernanda Ywasaki $^{2}$
Andre Marcelo
Conceição Meneses
Angelo Valentim
Martins
João Maria do Amaral
Júnior
Hilma Lúcia Tavares
Dias
Silvio Arruda
Vasconcellos

${ }^{1}$ UFPA, Avenida Maximino Porpino, n. 1000, 68740-000 - Castanhal, PA - Brasil.

${ }^{2}$ USP, FMVZ, Av. Prof. Dr. Orlando Marques de Paiva, 05508-270 - SP SP - Brasil.

${ }^{3}$ Adepará, Avenida Júlio César 5000, 66617-420, Belém - PA. Brasil.

${ }^{4} U$ fra. Av. Tancredo Neves, 2505, 66077-530, Belém, Pará, Brasil.

Recebido: 09/04/2009

Aprovado: 19/08/2010

AUTOR CORRESPONDENTE:

Carla Cristina Guimarães de Moraes E-mail:ccmoraes@ufpa.br

PALAVRAS-CHAVE:

Leptospirose, Equídeos, Soroaglutinação Microscópica (SAM), Pará

KEY WORDS:

Equine leptospirosis, microscopical seroagglutination test, Pará.

\section{Pesquisa de anticorpos para sorovares de Leptospira interrogans patogênicas em equídeos criados na ilha de Algodoal, Estado do Pará}

\author{
A study of anti-Leptospira interrogans \\ antibodies in horses bred on Algodoal island, \\ in the Brazilian State of Pará
}

Resumo: Neste estudo, avaliou-se a ocorrência de anticorpos contra Leptospira interrogans em função da taxonomia em equídeos da ilha de Algodoal/Pará, verificando a distribuição dos sorovares em relação a sexo e faixa etária dos animais. Foram utilizadas 37 amostras de soro de animais adultos, submetidas ao teste de soroaglutinação microscópica, em que todos reagiram a um ou mais sorovares de Leptospira interrogans, perfazendo $100 \%(37 / 37)$ de reagentes na titulação $1: 100$. O maior percentual de reagentes foi observado para o sorovar Australis, com $54,05 \%$ (20/37). Observou-se um maior percentual de amostras reagentes ao sorovar Australis nos machos, enquanto, em fêmeas o mais frequente foi o sorovar Sentot. De acordo com a faixa etária, no grupo 1 (2 a 7 anos) foi obtido maior número de amostras reagentes para o sorovar Cynopteri, com 36,36\% (8/22), no grupo 2 (> 7 a 13 anos) os sorovares Butembo e Sentot reagiram igualmente em 60,0\% (6/10) das amostras e no grupo 3 (> 13 anos) observou-se 100\% (5/5) de reação para o sorovar Pyrogenes. Desse modo, o estudo possibilitou concluir que houve uma variedade de sorovares de Leptospira interrogans ocorrendo em equídeos, na ilha de Algodoal (PA), uma vez que os 37 equídeos testados foram positivos ao método de soroaglutinação microscópica.

Abstract: This study evaluated the occurrence of antibodies against Leptospira interrogans in horses on Algodoal island/in the Brazilian State of Pará, establishing the distribution of serovars with respect to the sex and age of animals. The study used 37 serum samples from adult animals that were subjected to the microscopical seroagglutination test, in which $100 \%(37 / 37)$ were reagents in the titration $1: 100$ to one or more serovars of Leptospira interrogans. The highest percentage of reagents was observed for the Australis serovar with 54.05\% (20/37). Males showed a higher frequency of reaction to the Australis serovar, while females reacted more to Sentot. With regard to age, in group 1 ( 2 to 7 years) most samples reacted to the Cynopteri serovar (36.36\% (8/22)); in group 2 ( $>7$ to 13 years) both Butembo and Sentot serovars responded equally (60.0\% $(6 / 10)$ ), and in group 3 (> 13 years) $100 \%$ (5/5) samples reacted to the Pyrogenes serovar. This study therefore leads to the conclusion that a variety of Leptospira interrogans can occur in the horses of the island of Algodoal (PA), since 37 of the horses tested positive to the microscopical seroagglutination test. 


\section{Introdução}

A leptospirose é uma zoonose bacteriana de ampla distribuição mundial, causada por espiroquetas patogênicas do gênero Leptospira, que acomete diversas espécies de animais domésticos, selvagens, inclusive o homem (BRASIL, 2005; LOMAR et al., 2005).

Os animais participam da cadeia epidemiológica como hospedeiros naturais dos sorovares de Leptospira sp., disseminando a infecção por meio da urina, que contamina o ambiente, assim como chuvas e enchentes propiciam a disseminação do agente para outros animais e o homem. Este último é considerado hospedeiro acidental, com pouca eficiência na perpetuação desta enfermidade (REZENDE et al., 1997; LOMAR et al., 2005).

Com a maior incidência de chuvas durante o período de inverno paraense, assim como chuvas moderadas no verão, cresce a possibilidade do aparecimento de casos de leptospirose, doença que, se não tratada na primeira semana de contaminação, pode levar à morte (DE PAULA et al., 2005).

Em 1947, na Rússia, foi publicado o primeiro relato de ocorrência natural de leptospirose equina (LEES; GALE, 1994). Nesta espécie, a infecção caracteriza-se geralmente como assintomática, embora possa manifestar-se com sintomatologia aguda e de evolução associada com uveíte recorrente, abortamentos e outros sinais sistêmicos (ROMERO et al., 1994; GENOVEZ et al., 2004).

A leptospirose é uma doença socioeconômica que acarreta sérios danos à saúde humana e animal, em virtude das condições ambientais inapropriadas, precárias condições de infraestrutura e sanitárias, alta infestação de roedores infectados. Indivíduos com baixo nível de escolaridade e remuneração são os mais atingidos, apresentando índices elevados para essa doença (BRASIL, 2005). Até o presente momento, não existem dados soro-epidemiológicos precisos e capazes de demonstrar o impacto econômico e social da leptospirose equina no Brasil, em particular na Região Nordeste do Estado do Pará. Vários fatores contribuem para agravar esta situação, tais como: a grande extensão territorial, a escassez dos serviços de saúde e de recursos médicos em muitas regióes, a deficiente educação sanitária de grande parte da população e contatos cada vez mais estreitos com os animais domésticos.

De acordo com os dados da pesquisa pecuária municipal do IBGE (2008), o Estado do Pará possui um efetivo de rebanho de 408.561 equídeos. O município de Maracanã/PA que está localizado na microrregião do Salgado do Estado, possui um efeti- vo de 265 equídeos (IBGE, 2008), sendo que este município abrange geograficamente a ilha de Maiandeua, que também é conhecida popularmente por ilha de Algodoal e que possui um efetivo de rebanho equídeo de 60 animais aproximadamente (IBGE, 2008; ALGODOAL, 2009).

O objetivo deste estudo foi avaliar a ocorrência de anticorpos contra Leptospira interrogans em equídeos da ilha de Algodoal/Pará, verificando a distribuição dos sorovares em relação a sexo e faixa etária dos animais.

\section{Material e Métodos}

No presente estudo foram utilizados 37 equídeos, de ambos os sexos, diferentes idades, sem raça definida e sem apresentação de qualquer sintomatologia clínica da enfermidade. Os soros foram obtidos, após autorização prévia dos proprietários, de maneira aleatória, durante o mês de fevereiro do ano de 2007 (não foi autorizada pelos proprietários a colheita de sangue dos demais 23 equídeos presentes na ilha). Por ocasião da coleta, cada animal foi cadastrado em formulário próprio, contendo identificação do proprietário e dados com informações sobre a idade, sexo, espécie e histórico de vida reprodutiva do animal.

As idades foram estimadas pela modificação na face oclusal (mesa dentária, de ovalada a biangular), pela erupção continuada dos dentes e pelo desgaste de seus elementos constituintes. Desta forma, foram constituídos três grupos distintos: animais de 2 a 7 anos (grupo 1, n = 22 animais), >7 a 13 anos (grupo $2, \mathrm{n}=10$ animais) e $>13$ anos (grupo 3, $\mathrm{n}=5$ animais) (SILVA et al., 2003).

As amostras de sangue foram colhidas de modo asséptico, por método de venopunção da jugular, com auxílio de agulhas descartáveis estéreis $40 \mathrm{~mm} \mathrm{X}$ 1,2 mm (18G), em tubos estéreis de $10 \mathrm{ml}$, sem anticoagulante. Após a retração do coágulo, as amostras foram centrifugadas a $2500 \mathrm{~g}$, por $10 \mathrm{~min}$. Em seguida, foram acondicionadas em microtubos de polipropileno de $1,5 \mathrm{~mL}$ devidamente identificados e conservados a $-20{ }^{\circ} \mathrm{C}$ até o momento da realização das provas sorológicas.

O diagnóstico sorológico foi realizado no Laboratório de Investigação e Diagnóstico em Enfermidades Animais (Lidea) do Centro de Biologia da Universidade Federal do Pará em Belém, PA.

Foram utilizadas como antígenos para a prova de Soroaglutinação Microscópica (SAM) as culturas de cepas-padrão de 21 sorovares de Leptospira interrogans, 
vivas, mantidas em repiques semanais, provenientes do Departamento de Medicina Veterinária Preventiva e Saúde Animal da Faculdade de Medicina Veterinária e Zootecnia da Universidade de São Paulo.

Seguindo o protocolo para a realização da prova de SAM, foram utilizados soros controle positivo e negativo para validar os resultados deste estudo. Durante a fase de triagem, cada soro-teste foi diluído na proporção 1:50 em solução $\mathrm{PBS}^{1}, \mathrm{pH}$ 7,5. Em microplacas de polietileno, com fundo em "U", foram depositados $50 \mu \mathrm{L}$ de soro diluído 1:50, em seguida foram adicionados $50 \mu \mathrm{L}$ de suspensões antigênicas, e então cada amostra passou a ter diluição final de 1:100. As placas permaneceram incubadas em estufa a $29^{\circ} \mathrm{C}$, durante duas horas consecutivas. Ao final deste período, foi realizada a leitura, em lâminas sem lamínulas, através de microscopia em campo escuro, sob objetiva de 10X e ocular de 10X a 15X, sendo observado o grau de aglutinação das Leptospiras. Todas as amostras que apresentaram grau de aglutinação igual ou superior a $50 \%$ foram encaminhadas para a titulação.

A fase de titulação foi iniciada a partir da diluição 1:100 utilizada na triagem, e foram realizadas diluições seriadas geométricas de razão dois em cada soro a ser testado, a fim de se observar em qual diluição se extinguiriam as aglutinações $\geq$ a $50 \%$. O protocolo de incubação e leitura da microplaca assemelhou-se ao da fase de triagem.

Neste estudo, foi calculada a prevalência sorológica em 37 amostras de equídeos (que representam 61,7\% da população total de equídeos na ilha de Maiandeua), testadas para 21 sorovares de Leptospira sp na prova de SAM. Foi realizado o cálculo de distribuição de frequências de soros de equídeos reagentes à Leptospira sp, segundo o sorovar, sexo e grupo etário.

\section{Resultados}

Das 37 amostras de soros avaliadas, 100\% (37/ 37) apresentaram reação frente a um ou mais sorovares de Leptospira interrogans pela Soroaglutinação Microscópica (SAM) com título igual a 100. Apenas o sorovar Copenhageni não reagiu com nenhuma das amostras testadas.

O sorodiagnóstico para leptospirose nos equídeos de Algodoal revelou um maior percentual de amostras reagentes para o sorovar Australis, com
54,05\% (20/37), seguido do sorovar Pyrogenes, com $48,65 \%$ (18/37). Com relação ao sexo dos animais estudados, foi notada uma maior ocorrência de reações para o sorovar Australis em machos, 55,55\% (15/27), enquanto 70,00\% (7/10) das fêmeas foram reagentes ao sorovar Sentot. Segundo a faixa etária, o sorovar Australis foi reagente em 54,54\% (12/22) dos animais pertencentes ao grupo um, enquanto no grupo dois os sorovares Sentot e Butembo reagiram igualmente em 60\% (6/10) dos animais; entretanto, foi encontrado, no grupo três, $100 \%(5 / 5)$ de animais reagentes para o sorovar Pyrogenes (Tabela 1).

Tabela 1 - Distribuição dos resultados das análises laboratoriais pelo método de Soroaglutinação Microscópica (SAM) para pesquisa de anticorpo anti-Leptospira de acordo com os sorovares, grupos de faixa etária (Grupo $1=2$ a 7 anos, Grupo $2=>7$ a 13 anos e Grupo $3=>13$ anos) e sexo (macho $e$ fêmeas) dos equídeos da ilha de Algodoal, Pará, 2009.

\begin{tabular}{|c|c|c|c|c|c|c|}
\hline \multirow[b]{2}{*}{ SOROVARES } & \multirow[b]{2}{*}{ GERAL } & \multicolumn{3}{|c|}{ FAIXA ETÁRIA } & \multicolumn{2}{|c|}{ SEXO } \\
\hline & & $\begin{array}{l}\text { GRUPO } 1 \\
\text { (2 a } 7 \text { anos) }\end{array}$ & $\begin{array}{l}\text { GRUPO } 2 \\
\text { (>7 a } 13 \text { anos) }\end{array}$ & $\begin{array}{l}\text { GRUPO } 3 \\
\text { ( }>13 \text { anos) }\end{array}$ & Machos & Fêmeas \\
\hline Andamana & $\begin{array}{c}6 \\
(16,22 \%)\end{array}$ & $\stackrel{3}{3}(13,61 \%)$ & $\begin{array}{c}3 \\
(30 \%)\end{array}$ & 0 & $\begin{array}{c}4 \\
(14,81 \%)\end{array}$ & $\begin{array}{c}2 \\
(20,00 \%)\end{array}$ \\
\hline Australis & $\begin{array}{l}20 \\
(54.04 \%)\end{array}$ & $\begin{array}{c}12 \\
(54,54 \%)\end{array}$ & $\begin{array}{c}5 \\
(50 \%)\end{array}$ & $\begin{array}{c}3 \\
(60 \%)\end{array}$ & $\begin{array}{c}15 \\
(55.55 \%)\end{array}$ & $\begin{array}{c}5 \\
5 \\
(50,00 \%)\end{array}$ \\
\hline Bataviae & 5 & 2 & 2 & 1 & 3 & $\begin{aligned} 2 \\
2\end{aligned}$ \\
\hline Bratislava & $\begin{array}{c}(13,51 \%) \\
1 \\
(2,7 \%)\end{array}$ & $\begin{array}{c}(9,09 \%) \\
0\end{array}$ & $\begin{array}{c}(20 \%) \\
1 \\
(10 \%)\end{array}$ & $\begin{array}{c}(20 \%) \\
0\end{array}$ & $\begin{array}{c}(11,11 \%) \\
1 \\
(3,70 \%)\end{array}$ & $\begin{array}{c}(20,00 \%) \\
0\end{array}$ \\
\hline Butembo & $\begin{array}{c}10 \\
(27.03 \%)\end{array}$ & $\begin{array}{c}2 \\
(9,09 \%)\end{array}$ & $\begin{array}{c}6 \\
60 \%)\end{array}$ & $\begin{array}{c}3 \\
(60 \%)\end{array}$ & $\begin{array}{c}9 \\
(33,33 \%)\end{array}$ & $\begin{array}{c}2 \\
(20,00 \%)\end{array}$ \\
\hline Canicola & $\begin{array}{l}11 \\
(29,73 \%)\end{array}$ & $\begin{array}{c}(5,0) \\
5 \\
(22,72 \%)\end{array}$ & $\begin{array}{c}3 \\
30 \%)\end{array}$ & $\begin{array}{l}(00) \\
3 \\
(60 \%)\end{array}$ & $\begin{array}{c}(00,00 / 0) \\
6 \\
(22,22 \%)\end{array}$ & $\begin{array}{c}(0,00) \\
3 \\
(30,00 \%)\end{array}$ \\
\hline Castellonis & $\begin{array}{c}4 \\
(10,81 \%)\end{array}$ & $\begin{array}{l}1 \\
(4,54 \%)\end{array}$ & $\begin{array}{c}2 \\
(20 \%)\end{array}$ & $\begin{array}{c}1 \\
(20 \%)\end{array}$ & $\begin{array}{l}1 \\
(3,70 \%)\end{array}$ & $\begin{array}{c}3 \\
(30,00 \%)\end{array}$ \\
\hline Cynopteri & $\begin{array}{c}16 \\
(43,24 \%)\end{array}$ & $\begin{array}{c}8 \\
(36,36 \%)\end{array}$ & $\begin{array}{c}5 \\
(50 \%)\end{array}$ & $\begin{array}{c}3 \\
(60 \%)\end{array}$ & $\begin{array}{c}10 \\
(37,04 \%)\end{array}$ & $\begin{array}{c}6 \\
(60,00 \%)\end{array}$ \\
\hline Copenhageni & 0 & 0 & 0 & 0 & 0 & 0 \\
\hline Hardjo & $\begin{array}{c}11 \\
(29,73 \%)\end{array}$ & $\begin{array}{c}7 \\
(31,81 \%)\end{array}$ & $\begin{array}{c}4 \\
(40 \%)\end{array}$ & $\begin{array}{c}1 \\
(20 \%)\end{array}$ & $\stackrel{7}{7}(25,92 \%)$ & $\begin{array}{c}4 \\
(40,00 \%)\end{array}$ \\
\hline Hebdomadis & $\begin{array}{c}6 \\
(16,22 \%)\end{array}$ & $\begin{array}{c}2 \\
(9,09 \%)\end{array}$ & $\begin{array}{c}1 \\
(10 \%)\end{array}$ & $\begin{array}{l}2 \\
(40 \%)\end{array}$ & $\begin{array}{c}4 \\
4 \\
(14,81 \%)\end{array}$ & $\begin{array}{c}1 \\
(10,00 \%)\end{array}$ \\
\hline Icterohaemorrhagiae & $\begin{array}{l}11 \\
(29,73 \%)\end{array}$ & $\begin{array}{l}7 \\
(31,81 \%)\end{array}$ & $\begin{array}{c}2 \\
(20 \%)\end{array}$ & $\begin{array}{c}2 \\
(40 \%)\end{array}$ & $(29,63 \%)$ & $\begin{array}{c}3 \\
(30,00 \%)\end{array}$ \\
\hline Javanica & $\begin{array}{c}1 \\
(2,7 \%)\end{array}$ & $\begin{array}{c}1 \\
(4,54 \%)\end{array}$ & 0 & 0 & $\begin{array}{l}1 \\
(3,70 \%)\end{array}$ & 0 \\
\hline Panamá & $\begin{array}{c}4 \\
(10,81 \%)\end{array}$ & $\begin{array}{c}2 \\
(9,09 \%)\end{array}$ & $\begin{array}{c}2 \\
(20 \%)\end{array}$ & $\begin{array}{c}1 \\
(20 \%)\end{array}$ & $\begin{array}{c}4 \\
(14,81 \%)\end{array}$ & $\begin{array}{c}1 \\
(10,00 \%)\end{array}$ \\
\hline Patoc & $\begin{array}{c}1 \\
(2,7 \%)\end{array}$ & 0 & 0 & $\begin{array}{c}1 \\
(20 \%)\end{array}$ & $\begin{array}{c}1 \\
(3,70 \%)\end{array}$ & 0 \\
\hline Pyrogenes & $\begin{array}{c}18 \\
(48,65 \%)\end{array}$ & $\begin{array}{c}11 \\
(50,00 \%)\end{array}$ & $\stackrel{2}{2} \%$ & $\begin{array}{c}5 \\
(100 \%)\end{array}$ & $\begin{array}{c}12 \\
(44,44 \%)\end{array}$ & $\begin{array}{c}6 \\
(60,00 \%)\end{array}$ \\
\hline Sentot & $\begin{array}{c}17 \\
(45,95 \%)\end{array}$ & $\begin{array}{c}7 \\
(31,81 \%)\end{array}$ & $\begin{array}{c}6 \\
(60 \%)\end{array}$ & $\begin{array}{c}4 \\
(80 \%)\end{array}$ & $\begin{array}{c}10 \\
(37,04 \%)\end{array}$ & $\begin{array}{c}7 \\
(70,00 \%)\end{array}$ \\
\hline Shermani & $(5,41 \%)$ & $\begin{array}{c}1 \\
(4,54 \%)\end{array}$ & $\begin{array}{c}1 \\
(10 \%)\end{array}$ & 0 & $\begin{array}{c}1 \\
(3,70 \%)\end{array}$ & 0 \\
\hline Tarassovi & $\begin{array}{c}2 \\
(5,41 \%)\end{array}$ & $\begin{array}{c}1 \\
(4,54 \%)\end{array}$ & 0 & 0 & $\begin{array}{c}1 \\
(3,70 \%)\end{array}$ & $\begin{array}{c}1 \\
(10,00 \%)\end{array}$ \\
\hline Whitcombi & $\begin{array}{c}1 \\
(2,7 \%)\end{array}$ & 0 & $\begin{array}{c}1 \\
(10 \%)\end{array}$ & 0 & 0 & $\begin{array}{c}1 \\
(10,00 \%)\end{array}$ \\
\hline Wolffi & $\begin{array}{c}1 \\
(2,7 \%)\end{array}$ & $\begin{array}{c}1 \\
(4,54 \%)\end{array}$ & 0 & 0 & 0 & $\begin{array}{c}1 \\
(10,00 \%)\end{array}$ \\
\hline Subtotal & 37 & 22 & 10 & 5 & 27 & 10 \\
\hline Total & 37 & & 37 & & 37 & 7 \\
\hline
\end{tabular}

Seguindo o protocolo da prova de SAM, todas as amostras com reação aglutinante de grau e" a $50 \%$ na etapa de triagem foram encaminhadas para titulação; contudo, nenhuma delas foi reagente em diluições superiores a 1:100.

\footnotetext{
${ }^{1}$ Solução tamponada de Sorensen: $\mathrm{KH}_{2} \mathrm{PO}_{4}=1,09 \mathrm{~g} ; \mathrm{Na}_{2} \mathrm{HPO}_{4}=8,33 \mathrm{~g}$; água destilada=1000 $\mathrm{mL}$. $\mathrm{pH}$ final=7,6 Solução salina tamponada de Sorensen: Solução salina fisiológica $0,85 \%=1,840 \mathrm{~mL}+$ Solução tamponada de Sorensen $=160 \mathrm{~mL}$. $\mathrm{pH}$ final $=7,5$.
} 


\section{Discussões}

Antes de tudo, vale ressaltar que a ilha de Algodoal consiste em uma área territorial de $19 \mathrm{~km}^{2}$, circundada pelo oceano Atlântico. A população total de equídeos criados na ilha é de 60 animais e estes animais inevitavelmente compartilham os mesmos espaços entre si e com outras espécies, inclusive o homem.

Esta pesquisa objetivou investigar, pela primeira vez, a presença de anticorpos contra Leptospira interrogans em equídeos criados na ilha de Algodoal/PA. Com base nos resultados obtidos pelo método de SAM, este estudo revelou que $100 \%$ dos animais participantes desta análise foram reagentes, com títulos iguais a 100, para pelo menos um dos sorovares presentes em uma bateria contendo 20 sorovariedades de Leptospira interrogans, em que apenas o sorovar Copenhageni não reagiu com nenhuma das amostras estudadas. Assim sendo, estes resultados sugerem que os equídeos da ilha de Algodoal mantiveram contato, direto ou indireto, com fontes de infecção para a doença, possivelmente existente na região.

Estes dados se aproximam dos relatados por Romero et al. (1994), que realizaram um estudo no Estado de São Paulo envolvendo 922 amostras de equinos e observaram $87,5 \%$ de animais reagentes para a diluição 1:100. Igualmente, Faber et al. (2000) evidenciaram $85,70 \%$ de animais reagentes nesta diluição, ao examinarem o humor aquoso de 28 equinos com quadro clínico de uveíte recorrente. Adicionalmente, Aguiar et al. (2008) realizaram um amplo estudo com equídeos criados em propriedades do município de Monte Negro/RO, no qual empregaram a técnica de SAM para pesquisa de Leptospira interrogans. Na ocasião, encontraram 91,4\% de animais reagentes ao teste e ressaltaram que $82 \%$ das propriedades estudadas apresentaram, no mínimo, um equídeo reagente ao diagnóstico sorológico.

Porém, mesmo perante esta elevada taxa de animais sorologicamente reagentes para leptospirose, nenhum equídeo testado no presente estudo evidenciava qualquer sintomatologia da doença no momento da colheita de sangue, e este fato é coerente com o descrito na literatura por Romero et al. (1994); Genovez et al. (2004) e Pires Neto, Hesse e Oliveira (2005), que caracterizam a infecção nestes animais como geralmente assintomática, embora possa manifestar-se com sintomatologia aguda e de evolução associada com uveíte recorrente, abortamentos e outros sinais sistêmicos.

A alta ocorrência de reação para anticorpo con- tra Leptospira interrogans nos equídeos da ilha de Algodoal pode ser reflexo da relação entre o alto índice pluviométrico da região Amazônica e a forma de criação destes animais, uma vez que a associação destes fatores institui um ambiente propício para a transmissão da doença. Da mesma forma, esses resultados corroboram as colocações feitas por Hashimoto et al. (2007), quando referem que a leptospirose em equídeos ocorre com uma frequência considerável, dependendo da região e do grau de exposição desses animais a possíveis fontes de infecção. Adicionalmente, compartilhamos com Langoni et al. (2004) o pensamento de que a utilização de amostras únicas em testes sorológicos assegura apenas que os animais reagentes mantiveram contato prévio com o agente e, não necessariamente, são animais doentes.

Os dados aqui descritos fortalecem os argumentos de Hashimoto et al. (2007), os quais indicam os riscos de locais abandonados e/ou usados como depósitos de lixo a céu aberto, propícios à sobrevivência de roedores e outros potenciais transmissores de Leptospira interrogans, uma vez que as amostras testadas neste estudo foram obtidas a partir de equídeos destinados à tração, que vivem sob manejo inadequado e transitam em locais com condições precárias de saneamento básico.

Outros valores que discordam deste estudo, no que concerne à quantidade de animais reagentes, também foram descritos por Lillenbaum (1998), Langoni et al. (2004) e Linhares et al. (2005), que encontraram, respectivamente, 42,96\%, 54\%, 45,05\% de animais apresentando reação na diluição 1:100, para um ou mais sorovares de Leptospira interrogans em função da taxonomia, em análise sorológica de equídeos. Somando-se aos resultados discordantes com os aqui descritos encontra-se o estudo realizado por Rocha et al. (2004), em que apenas 37\% das amostras de soro provenientes de haras foram reagentes para leptospirose.

Em relação à prevalência de sorovares, a maior percentagem de evidências sorológicas foi identificada para o sorovar Australis, em que foram observadas 54,05\% das reações deste estudo. Resultados semelhantes foram relatados por Rocha et al. (2004), que também encontraram maior prevalência sorológica para a estirpe Australis (18,5\%) em uma pesquisa realizada com equinos criados em haras.

Em contrapartida, discordando de alguns dados deste estudo estão os resultados apresentados por Linhares et al. (2005) que, ao analisarem a prevalência dos sorovares de Leptospira interrogans em 
182 soros de equinos de uma microrregião de Goiânia, não encontraram nenhuma amostra reagente ao sorovar Australis pelo método de SAM. Em contrapartida, Pires Neto, Hesse e Oliveira (2005) desenvolveram um levantamento sorológico no período de 2000 a 2003 e encontraram apenas 9,63\% de soros de equídeos reagentes para este sorovar.

No presente estudo, também foi notada uma elevada positividade para o sorovar Pyrogenes, o qual reagiu em 48,64\% das amostras testadas. Contudo, este resultado contrasta com os dados apresentados por Linhares et al. (2005), que em sua pesquisa não observaram nenhum animal reagente para esse sorovar.

O sorovar Icterohaemorrhagiae foi reagente em $29,73 \%$ das amostras testadas, se apresentando como o quinto sorovar mais reagente nas amostras sorológicas dos equídeos da ilha de Algodoal. Mesmo que não tenha sido o mais prevalente, o valor referente à ocorrência de Icterohaemorrhagiae neste estudo foi muito superior ao encontrado por Aguiar et al. (2008), que observaram apenas 8,7\% de reações positivas para este sorovar, em equídeos do Município de Monte Negro/RO. Como a ocorrência deste sorovar sugere o envolvimento de roedores sinantrópicos, é natural que na ilha de Algodoal se observe uma frequência considerável para este sorovar, uma vez que a estrutura socioeconômica e cultural da ilha propicia a manutenção destes reservatórios.

Ainda complementam este estudo os resultados encontrados para os sorovares Patoc, Javanica, Whitcombi, Wolffi e Bratislava, em que cada sorovar prevaleceu igualmente em $2,70 \%$ das amostras testadas. No entanto, estes achados discordam dos resultados relatados por Pires Neto, Hesse e Oliveira (2005), que referiram o sorovar Bratislava como sendo o mais prevalente em seu levantamento epidemiológico, ocorrendo em 19,82\% dos equinos analisados.

Igualmente, Aguiar et al. (2008), durante uma pesquisa envolvendo eqüídeos do município de Monte Negro/RO, também apontaram a ocorrência de Bratislava em 10,5\% das amostras reagentes, e dessa forma foi considerado o sorovar mais prevalente naquele estudo. A extensa constância na identificação do sorovar Bratislava, associada à ausência de sintomatologia clínica nos animais reagentes, fortalece a hipótese de adaptação desta bactéria à espécie equina. Entretanto o sorovar Bratislava é frequentemente relacionado com a infecção de suínos; contudo, na ilha de Algodoal há poucas criações de suínos e os equídeos da ilha não possuem acesso fácil a estes animais.

$\mathrm{O}$ achado que corresponde à ocorrência do sorovar Patoc nos equídeos usados neste estudo possui grande importância diagnóstica, uma vez que Patoc é um sorovar pertencente ao gênero Leptospira biflexa que, contrariamente à Leptospira interrogans, é uma bactéria saprófita e de vida livre. Ademais, a utilização deste sorovar nas coleções antigênicas empregadas no diagnóstico da leptospirose animal é justificada pela característica de reação sorológica precoce e pelos relatos de reações cruzadas com alguns sorovares patogênicos, Diante disso, o sorovar Patoc pode ser utilizado na rotina diagnóstica como um indicador que possui o atributo de reduzir o tempo necessário para a identificação sorológica do agente.

Este estudo expôs uma diferença entre os sorovares predominantes na análise da variável sexo, de tal modo que o sorovar Australis foi identificado reagindo em 55,55\% (15/27) das amostras de machos, enquanto o sorovar Sentot foi observado em $70,00 \%(7 / 10)$ dos soros das fêmeas.

A distribuição dos animais relacionada à faixa etária demonstrou diferença significativa de acordo com os diferentes grupos; entretanto, observou-se $54,54 \%$ de amostras reagentes ao sorovar Australis no grupo $1,60 \%$ de animais reagentes aos sorovares Sentot e Butembo no grupo 2 e 100\% das amostras do grupo 3 reagiram ao sorovar Pyrogenes. No entanto, estes resultados discordam dos obtidos por Kitson-Piggot e Prescott (1987), que relataram uma maior ocorrência do sorovar Bratislava em equídeos de diversas faixas etárias.

Este estudo possibilitou verificar a ocorrência de uma grande variedade de sorovares de Leptospira interrogans acometendo os equídeos habitantes da ilha de Algodoal/Pará, e este achado pode implicar em um provável reflexo dos sorovares mantidos por outros animais domésticos ou selvagens que vivem na mesma região geográfica.

A relevância deste estudo está na evidente ocorrência de anticorpos para sorovares de Leptospira nos equídeos da ilha de Algodoal, atentando principalmente para o aspecto sócioeconômico regional e de saúde animal. Com relação aos riscos à saúde pública, apesar de não existirem relatos de casos de transmissão de leptospirose equina para os humanos, vale ressaltar que a doença é uma das mais importantes zoonoses da atualidade, cujos aspectos clínicos e epidemiológicos devem ser bem elucidados, visando minimizar os riscos desta enfermidade em humanos. 
Outro ponto de relevância observado neste estudo foi a atenção voltada para a ilha de Algodoal, uma vez que o local é considerado um dos mais importantes sítios de veraneio do Estado do Pará, onde os equídeos são frequentemente utilizados como meio de transporte. Inevitavelmente, os turistas que visitam a ilha têm contato com os animais e isto pode favorecer a disseminação da infecção, pois nesta região não existe nenhum tipo de assistência veterinária e nem projetos de prevenção e educação sanitária para esclarecimento de enfermidades que ponham em risco a saúde da população.

\section{Conclusões}

A realização deste estudo permite afirmar que os equídeos da ilha de Algodoal estão sujeitos à infecção leptospírica, por existir uma grande variedade de sorovares de Leptospira interrogans circulantes na ilha. Mesmo que os equídeos não representem importante risco epidemiológico à saúde pública, a identificação de reagentes a pelo menos um sorovar de Leptospira SP alerta para a possível existência de reservatórios de estirpes patogênicas para outros animais e o homem. Vale ressaltar que os achados aqui expressos sugerem a necessidade de uma investigação mais intensa sobre a epidemiologia da leptospirose animal na ilha de Algodoal.

\section{Referências}

AGUIAR, D.M.; CAVALCANTE, G.T.; LARA, M.C.C.S.H.; VILLALOBOS, E.M.C.; CUNHA, E.M.S.; OKUDA, L.H.; STÉFANO, E.; NASSAR, A.F. C.; SOUZA, G.O.; VASCONCELLOS, S.A.; LABRUNA, M.B.; CAMARGO, L.M.A.; GENNARI, S.M. Prevalência de anticorpos contra agentes virais e bacterianos em equídeos do Município de Monte Negro, Rondônia, Amazônia Ocidental Brasileira. Brazilian Journal of Veterinary Research and Animal Science, São Paulo, v. 45, n. 4, p. 269-276, 2008.

BRASIL. Ministério da Saúde. Secretaria de Vigilância em Saúde. Guia de Vigilância Epidemiológica, 6. ed. Brasília: Ministério da Saúde, 2005. p. 502-507.

ENRIETTI, M.A. Contribuição ao conhecimento da incidência de Leptospiras em murídeos, caninos e suínos no Paraná. Brazilian Archives of Biology and Technology. v. jubilee (1946-2001), p.311-342, 2001.

FABER, N.A.; CRAWFORD, M.; LeFEBVRE, R.B.; BUYUKMIHCI, N.C.; MADIGAN, J.E.; WILIITS, N.H. Detection of Leptospira spp. in the aqueous humor of horses with naturally acquired recurrent Uveites. Journal of Clinical Microbiology, v. 38, n. 7, p. 2731-2733, 2000.

GENOVEZ, M.E.; SCARCELLI, E.; PIATTI, R.M.; GIRIO, R. J.S.; CARDOSO, M.V.; MIYASHIRO, S.; CASTRO, V. Leptospira spp. em sêmen de garanhão PSI detectada pela reação da Polimerase em Cadeia (PCR) - Relato de caso. Arquivo do Instituto Biológico, São Paulo, v. 71, (supl.), p. 546-548, 2004.

HASHIMOTO, V.Y.; GONÇALVES, D.D.; SILVA, F.G.; OLIVEIRA, R.C.; ALVES, L.A.; REICHMANN, P.; MULIER, E.E.; FREITAS, J.C. Occurrence of antibodies against leptospira spp. in horses of the urban area of Londrina, Paraná, Brazil. Revista doInstituto de Medicina Tropical de São Paulo, v. 49, n. 5, p. 327-330, 2007.

KITSON-PIGGOT, A.W.; PRESCOTT, J.F. Leptospirosis in horses in Ontario. Canadian Journal of Veterinary Reseach, v. 51, n. 4, p. 448-451, 1987.

LANGONI, H.; SILVA, A.V.; PEZERICO, S.B.; LIMA, V.Y. Anti-leptospire agglutinins in Equine Sera, from São Paulo, Goias, and Mato Grosso do Sul, Brazil, 1996-2001. Journal of Venomous Animals and Toxins Including Tropical Diseases, v. 10, n. 3, p. 207-218, 2004.

LEES, V.W.; GALE, S.P. Titers to Leptospira species in horses in Alberta. The Canadian Veterinary Journal, v.10, n. 35, p. 636-640, 1994.

LILENBAUM, W. Leptospirosis on animal reproduction: IV. Serological findings in Mares from six farms in Rio de Janeiro, Brazil (1993-1996). Brazilian Journal Veterinary Reseach Animal Science, São Paulo, v. 35, n. 2, p. 61-63, 1998.

LINHARES, G.F.C.; GIRIO, R.J.S.; LINHARES, D.C.L.; MONDEIRO, L.C.; OLIVEIRA, A.P.A. Sorovares de Leptospira interrogans e respectivas prevalências em cavalos da Microrregião de Goiânia. Ciência Animal Brasileira, v. 6, n. 4, p. 255-259, 2005.

LOMAR, A.V.; VERONESI, R.; BRITO, T.; DIAMENT, D. Leptospiroses. In: VERONESI, R.; FOCACCIA, R. Tratado de infectologia. 3.ed. São Paulo: Atheneu, 2005. v.2, cap. 79, p. 987-1003.

MYERS, D. M. Serological studies and isolations of Serotype Hardjo and Leptospira biflexa strains from horses of Argentina. Journal of Clinical Microbiology, v. 3, n. 6, p. 548-55, 1976.

PIRES NETO, J.A.S.; HESSE, F.; OLIVEIRA, M.A.M. Leptospirose equina: aspectos clínicos, tratamento, prevenção e levantamento sorológico. Revista Veterinária em Foco, v. 2, n. 2, 2004/2005.

REZENDE, M.B.; LAINSON-LINS, Z.C.; BICHARA, C.N.C.; LEÃO, R.N.Q; COSTA, P.M.; JUNIOR, A.B.R. Leptospirose. In: LEAO, R.N.Q. Doenças infecciosas e parasitárias: enfoque Amazônico. Belém: Cejup/Uepa: Instituto Evandro Chagas, 1997. p. 507-519.

ROCHA, T.; ELLIS, W.A.; MONTGOMERY, J.; GILMORE, C.; REGALLA, J.; BREM, S. Microbiological and serological study of Leptospirosis in horses at 
Slaughter: first isolations. Research in Veterinary Science, v.76, p. 199-202, 2004

ROMERO, E.C.; SAKATA, E.E.; PINTO, J.R.; YASUDA, P.H.; BRANDÃO, A.P. Search for agglutinating antibodies to Leptospira and Leptonema in horses, São Paulo, Brazil. Brazilian Journal Veterinary Reseach Animal Science, São
Paulo, v. 31, n. 3/4, p. 210-215, 1994.

SILVA, M.F.; GOMES, T.; DIAS, A.S.; MARQUES, J.A.; JORGE, L.M.; FAÍSCA, J.C.; PIRES, G.A.; CALDEIRA, R. M. Estimativa da idade dos equinos através do exame dentário. Revista Portuguesa de Ciências Veterinárias, v. 98, n. 547, p. 103-110, 2003. 